Article

\title{
$e$ LoriCorps Immersive Body Rating Scale and $e$ LoriCorps Mobile Versions: Validation to Assess Body Image Disturbances from Allocentric and Egocentric Perspectives in a Nonclinical Sample of Adolescents
}

\author{
Johana Monthuy-Blanc ${ }^{1,2}$, Giulia Corno ${ }^{1,3, *}$, Marilou Ouellet ${ }^{1} \mathbb{D}$, Fadel Touré ${ }^{1}$, Francisca Bourbeau ${ }^{1}$ \\ Michel Rousseau ${ }^{1}$, Audrey Charette ${ }^{1}$, Nicolas Moreau 1,4 ${ }^{(D)}$, Normand Roy 1,5 ${ }^{1}$, Vicky Drapeau ${ }^{6}$, \\ Marie-Eve Mathieu ${ }^{7}$ (D) and Stéphane Bouchard ${ }^{1,3,8}$ (D)
}

check for updates

Citation: Monthuy-Blanc, J.; Corno, G.; Ouellet, M.; Touré, F.; Bourbeau,

F.; Rousseau, M.; Charette, A.;

Moreau, N.; Roy, N.; Drapeau, V.; et al. $e$ LoriCorps Immersive Body Rating Scale and $e$ LoriCorps Mobile Versions: Validation to Assess Body Image Disturbances from Allocentric and Egocentric Perspectives in a Nonclinical Sample of Adolescents. J. Clin. Med. 2022, 11, 1156. https:// doi.org/10.3390/jcm11051156

Academic Editor: Michele Roccella

Received: 23 December 2021

Accepted: 19 February 2022

Published: 22 February 2022

Publisher's Note: MDPI stays neutral with regard to jurisdictional claims in published maps and institutional affiliations.

Copyright: (C) 2022 by the authors. Licensee MDPI, Basel, Switzerland. This article is an open access article distributed under the terms and conditions of the Creative Commons Attribution (CC BY) license (https:// creativecommons.org/licenses/by/ $4.0 /)$.
1 GR2TCA-Loricorps-Groupe de Recherche Transdisciplinaire des Troubles du Comportement Alimentaire, Université du Québec à Trois-Rivières, 3351, Boulevard des Forges, Trois-Rivières, QC G8Z 4M3, Canada; johana.monthuy-blanc@uqtr.ca (J.M.-B.); marilou.ouellet@uqtr.ca (M.O.); fadel.toure@uqtr.ca (F.T.); francisca.bourbeau@uqtr.ca (F.B.); michel.rousseau@uqtr.ca (M.R.); audrey.charette@uqtr.ca (A.C.); nicolas.moreau@uottawa.ca (N.M.); normand.roy@umontreal.ca (N.R.); stephane.bouchard@uqo.ca (S.B.)

2 Centre de Recherche de l'Institut Universitaire en Santé Mentale de Montréal, 7401 Rue Hochelaga, Montreal, QC H1N 3M5, Canada

3 Chaire de Recherche du Canada en Cyberpsychologie Clinique, Université du Québec en Outaouais, 283, Boul Alexandre-Taché, Gatineau, QC J8X 3X7, Canada

4 School of Social Work, University of Ottawa, 120 University, Office 12035, Ottawa, ON K1N 6N5, Canada

5 Groupe de Recherche Interuniversitaire sur l'Intégration Pédagogique des Technologies de l'Information et de la Communication, Université de Montréal, 90, Avenue Vincent-d’Indy, Montreal, QC H2V 2S9, Canada

6 Département D'éducation Physique, Faculté des Sciences de L'éducation, Université Laval, Pavillon de l'Éducation Physique et des Sports, Local 2214, 2320, Rue des Bibliothèques, Quebec, QC G1V 0A6, Canada; vicky.drapeau@fse.ulaval.ca

7 Chaire de Recherche du Canada en Activité Physique et Obésité Juvénile, Université de Montréal, Boulevard Édouard-Montpetit, Montreal, QC H3T 1J4, Canada; me.mathieu@umontreal.ca

8 Centre de Recherche du Centre Intégré de Santé et de Services Sociaux de l'Outaouais, 20 Rue Pharand, Gatineau, QC J9Y 6H9, Canada

* Correspondence: giulia.me.corno@gmail.com

Abstract: A growing number of studies have used virtual reality (VR) for the assessment and treatment of body image disturbances (BIDs). This study, conducted in a community sample of adolescents, documents the convergent and discriminant validity between (a) the traditional paperbased Figure Rating Scale (paper-based FRS), (b) the VR-based Body Rating Scale (eLoriCorps-IBRS 1.1), and (c) the mobile app-based Body Rating Scale (eLoriCorps-IBRS 1.1-Mobile). A total of 93 adolescents (14 to 18 years old) participated in the study. Body dissatisfaction and body distortion were assessed through the paper-based FRS, the eLoriCorps-IBRS 1.1 and the $e$ LoriCorps-IBRS 1.1-Mobile. Eating disorder symptoms, body image avoidance, and social physique anxiety were also measured. Correlation analyses were performed. Overall, the results showed a good and statistically significant convergence between allocentric perspectives as measured by the paper-based FRS, the $e$ LoriCorps-IBRS 1.1 and the $e$ LoriCorps-IBRS 1.1-Mobile. As expected, the egocentric perspective measured in VR produced different results from the allocentric perspective, and from cognitive-attitudinal-affective dimensions of BIDs, with the exception of body distortion. These differences support the discriminant validity of the egocentric perspective of $e$ LoriCorps-IBRS 1.1 and are consistent with emerging evidence, highlighting a difference between experiencing the body from an egocentric (i.e., the body as a subject) and allocentric (i.e., the body as an object) perspective. The egocentric perspective could reflect a perceptual-sensory-affective construction of BIDs, whereas allocentric measures seem to be more related to a cognitive-affective-attitudinal construction of BIDs. Moreover, the results support the validity of the $e$ LoriCorps-IBRS 1.1-Mobile with promising perspectives of implementation among young populations. 
Keywords: body dissatisfaction; body distortion; virtual reality; mobile application; convergent and discriminant validity; egocentric perceptual-sensory-affective dimension of body image

\section{Introduction}

\subsection{Body Image Disturbances}

Adolescence is marked by physical changes due to puberty and to the development of identity, which can be challenging in social contexts where standards of beauty are related to thinness and muscularity [1]. Body dissatisfaction is dramatically widespread among adolescents: studies have reported that $24 \%$ to $46 \%$ of adolescent females are dissatisfied with their bodies. The percentages for adolescent males were lower, $12-26 \%$, but still alarming [2-5]. Body image-related issues are associated with a very strong desire to lose weight and change body shape [6]. Indeed, according to Cazale, Paquette and Bernèche [7], 41\% of adolescent females report being dissatisfied with their body and wanting to be thinner, while $8 \%$ report wanting to be heavier. For males, the study revealed $24 \%$ want to be thinner, and $24 \%$ want to be heavier. Body image disturbances (BIDs, mainly body dissatisfaction and body distortion) are particularly relevant among youth, and especially during adolescence. During this period, BIDs present major risk factors for the development, maintenance and relapse of eating disorders (EDs) [8,9], such as anorexia nervosa, bulimia nervosa and binge eating disorder [10-15]. Some studies suggest that the level of body dissatisfaction can vary across different age groups [16,17]. However, other studies have found that body dissatisfaction seemed largely stable during a lifetime [5,18-20] and, considering the possible major consequences associated with BIDs, it is of paramount importance to identify and prevent BIDs, to promptly intervene before they become chronic, and to improve our understanding of the underlying factors that maintain BIDs.

Despite countless studies on body image, the definition of this concept is still not unanimous e.g., [21-23]. In this paper, body image is considered to be a multidimensional construct, indicating a personal and mental representation of one's physical appearance, which encompasses body-related cognitions, emotions, behaviors, and perceptions [24-26]. Body image dissatisfaction (which reflects the cognitive-affective dimension of BIDs) and body distortion (which reflects the perceptual dimension of BIDs) are two of the moststudied manifestations of BIDs [27-30]. Body image dissatisfaction refers to the extent people like or dislike the shape and/or size of their own body and whether they accept and value it [27]. Body distortion refers to a disturbance in accurately estimating one's own body size [27], and is observed when there is a difference between actual and perceived body size. The relation between these two dimensions remains an object of scientific debate [21]. Indeed, Cash and Deagle [27], and more recently Cornelissen et al. [31], suggested that attitudinal and perceptual components might represent two distinct phenomena. Nevertheless, several studies have proposed that BIDs may be driven by distorted attitudes toward a person's own body (i.e., body dissatisfaction), indicating that perceptual distortions could be explained solely in terms of changes in attitudinal body image $[21,32,33]$.

\subsection{Measures of BIDs}

To prevent BIDs in adolescence, it is important to be able to assess and promptly identify these disturbances. In the last few decades, several different tools were used to measure body image $[21,23,27]$. BIDs have usually been assessed through self-report questionnaires, such as the "Drive for Thinness" and "Body Dissatisfaction" subscales of the Eating Disorder Inventory 2 (EDI-2) [34], the Body Shape Questionnaire (BSQ) [35], the Body Image Avoidance Questionnaire (BIAQ) [36], and the Social and Physique Anxiety Scale [37]. In clinical and research settings, it is quite common to use body size estimation tasks (from the calculation of height and weight) to evaluate body distortion and body dissatisfaction using depictive or metric methods [21]. In depictive methods, participants are asked 
to estimate their perceived and ideal body size using figure rating scales (traditional paper-based FRS, 3D FRS) e.g., [38] or [39], deforming mirrors [40], and by deforming the entire body using photographs or videos [21,41-43]. With FRS, body size dissatisfaction is calculated by subtracting the ideal body size from the perceived body size, whereas body distortion corresponds to the participant's actual BMI minus the BMI of the perceived body size. In metric methods, participants are asked to indicate the size of different body parts (e.g., shoulders, hips, waist), for instance, with a rod, a caliper, or movable markers on a wall $[44,45]$. These distances of different body parts are then measured, for example, in centimeters. Thus, by depictive methods participants are asked to express their judgement on a global body appearance, whereas by metric methods participants are asked to focus on single and specific body parts [21]. Self-report questionnaires have been criticized as they often yield inconsistent and inconclusive results [23,46,47]. The alternative paper-based FRS has received criticism for employing figures that display unrealistic representations of a person's body, the lack of ecological validity due to the exclusive use of frontal displays (i.e., allocentric perspective), and the absence of figures that represent obesity [48]. To counter these limitations, a growing number of studies have recently explored the potential of virtual reality (VR) technologies by presenting scenarios through allocentric and egocentric (i.e., first person) perspectives $[47,49,50]$. The real-time rendering and exploration of the $3 \mathrm{D}$ images led to referring to virtual bodies, as opposed to only body figures, when describing the stimuli. VR allows assessment of BIDs from the same perspective as the paper-based FRS, which entails looking at bodies perceived as being presented in front of the person the allocentric perspective-(i.e., thirdperson point of view), and from a novel point of view, which involves looking at the body through one's eyes as if it is experienced as the person's own body-the egocentric perspective-(i.e., first-person point of view). Recently, researchers and clinicians started to investigate the nature and role of egocentric and allocentric body image perspectives. Indeed, Riva and Gaudio [51] proposed the Allocentric Lock Theory, which claims that: (a) the spatial allocentric perspective involves somatorepresentations (representations of the memory of the body and knowledge, beliefs, and attitudes about one's own body); (b) the spatial egocentric perspective involves somatoperceptions (perceptions of the actual state of the body and tactile stimuli from sensory inputs); and (c) individuals with—or at risk of developing —eating disorders are "locked" into a negative allocentric memory of their own body that is not adequately corrected by the information originating from the egocentric perspective [51-56]. Concretely, this manifests itself in an individual as a disruption in the way the body is experienced and remembered, and all the sensory information stored in short-term memory that could negate this disruption (e.g., significant weight loss) cannot change the allocentric (long-term memory) body perception that remains ingrained with rigidity. As a result, the maintenance of this misperception of the body is the result of the inability to update perceptual data in long-term memory [57].

\section{3. eLoriCorps-IBRS a VR-Based BIDs Assessment Tool}

In 1998, Riva and colleagues recreated, for the first time, a traditional paper-based FRS in VR. They developed the body image virtual reality scale (BIVRS) [58], which consisted of seven, and later nine, female and male virtual bodies ranging from underweight to overweight, displayed in an allocentric perspective. Since then, researchers have developed more realistic and inclusive versions of VR-based FRS- e.g., [46]. Traditionally, participants are asked to observe a line-up of 3D virtual bodies presented in an allocentric perspective and to select the body that corresponds to their perceived body size and their ideal body size. Recently, Monthuy-Blanc et al. [47] developed and documented the validity of the $e$ LoriCorps Immersive Body Rating Scale version 1.0 (eLoriCorps-IBRS 1.0). In this first version, users could observe seven virtual bodies matching their self-reported sex, ranging from underweight to overweight (i.e., BMI from 15.00 to $33.00 \mathrm{~kg} / \mathrm{m}^{2}$ ), presented both in an allocentric and egocentric perspective. As depicted in the article, $e$ LoriCorps-IBRS 1.0 replicated the exact same position as the paper-based FRS: virtual bodies have shoulders, 
arms and legs slightly rotated sideways. For each perspective, participants were asked to select their ideal and perceived body. The authors found a convergent validity of the allocentric ratings of the $e$ LoriCorps-IBRS 1.0 with the paper-based FRS. Results from the egocentric perspective revealed novel reflections about the nature of body image. Indeed, ideal body size and body dissatisfaction in the egocentric perspective differed when assessed by the allocentric VR-based versus paper-based FRS. However, the validity of the allocentric ratings from $e$ LoriCorps-IBRS 1.0 was investigated among the adult population. Moreover, the egocentric perspective has not yet been studied in adolescents.

Displaying the virtual bodies in the same position as the body figures in the paperbased FRS represented an attempt to limit the differences between the stimuli presented on paper and in VR. However, issues arose when experiencing the virtual bodies in the egocentric perspective. When immersed in VR looking down, participants saw their body as slightly turned to the right, with a prominent left shoulder and a body position that did not match their proprioception. The attempt to keep paper and VR versions similar for measuring body image may be impractical, as there are also other small differences, such as skin textures, details of the body and so forth. With the advent of future VR applications that could provide more body sizes than the seven original paper-based FRS, the possibility to select skin tone and texture as well as hair features that match those of the users, and tailor selected features of portions of the virtual bodies to patients' needs, the $e$ LoriCorps-IBRS 1.0 was slightly revised-eLoriCorps-IBRS version 1.1 ( $e$ LoriCorps-IBRS 1.1) - to position the virtual bodies as fully facing the users in the standard anatomical position with no body rotation. Given the growing need to assess adolescents' BIDs outside of the experimental research laboratory (e.g., ecological momentary assessment) with portable smartphone apps, an allocentric version of the virtual bodies was developed, the $e$ LoriCorps mobile application (eLoriCorps-IBRS 1.1-Mobile) to be validated specifically with adolescents.

\subsection{Objectives}

The current study bears two objectives. The first objective (O.1) is to assess the convergent validity between the allocentric perspective of BIDs measured with the paperbased FRS and eLoriCorps (-IBRS 1.1 and -IBRS 1.1-Mobile) in an adolescent sample. The convergent validity was expected to be high between the allocentric (paper, VR, mobile application) assessments of body dissatisfaction and body distortion. The second objective (O.2) is to test the discriminant validity between the egocentric perspective of BIDs measured with the VR-based $e$ LoriCorps-IBRS 1.1 and the allocentric perspective measured with paper-based FRS and eLoriCorps (-IBRS 1.1 and -IBRS 1.1-Mobile) in an adolescent sample. Consistently, with the adult validation study, it was expected that the egocentric VR perspective would yield results that were not strongly correlated with the allocentric (paper, VR, mobile application) measures of body dissatisfaction and perceptual body distortion [47]. Moreover, we explored the relationships between dimensions of BIDs in egocentric and allocentric perspectives and other constructs associated with BIDs, such as eating disorder symptoms (EDI-A), body image avoidance (BIAQ-A), and social physique anxiety (SPAS-12).

\section{Materials and Methods}

\subsection{Sample}

During recruitment, 84 females (80.77\%) and 20 males (19.23\%), all Caucasians and Canadian residents, expressed an interest in the study. Among these 84 females, 11 presented a prior or current presence of EDs. Adolescents with missing data were removed from the database, forming a final sample of 93 participants (72\% female and $28 \%$ male). Ages ranged from 14 to 18 years $(\mathrm{m}=15.4$ s.d. 1.01$)$. The average height, weight and BMI of the participants were, respectively, $1.66 \mathrm{~m}$ (s.d. 0.82), $61.1 \mathrm{~kg}$ (s.d. 10.85), and $22.3 \mathrm{~kg} / \mathrm{m}^{2}$ (s.d. 3.94). They were recruited at schools and community organizations which hold a partnership with the research group and had previously expressed an interest in 
eLoriCorps-IBRS 1.0. Inclusion criteria required that participants were French-speaking, self-identified as female or male, and aged between 14 and 18 years.

\subsection{Equipment and Material}

The study was conducted using the $e$ LoriCorps-IBRS 1.1 (see [47] for a detailed description of the first version of the VR-base scale). The virtual environment ran on an HP wx4600 PC computer ( $3 \mathrm{GHz}, 3.48$ GB RAM, ASUS GeForce 8800GTX graphics card; HewlettPackard, Montréal, QC, Canada), combined with Vuzix VR920 HMD (Vuzix, Rochester, New York, NY, USA), an InterSense Cube3 motion tracker (InterSense LLC, Billerica, MA, USA), and a hand-controlled joystick from a Wii RVL-003 (Nintendo Canada, Vancouver, $\mathrm{BC}$, Canada). The VR is based on Daydream Google technology. The $e$ LoriCorps mobile app runs on the Google Pixel 2 phone, Android 11 version (Octa-core $4 \times 2.35 \mathrm{GHz}$ Kryo and $4 \times 1.9 \mathrm{GHz}$ Kryo, 64 GB RAM, display AMOLED, 5.0 inches, $1080 \times 1920$ pixels) with a Google Daydream View headset and its Bluetooth controller. The e LoriCorps mobile application requires the Google View VR headset and controller. All designed by Google, MountainView, CA, USA.

\subsection{Assessment Measures}

The sociodemographic questionnaire included height, weight (to obtain body mass index, BMI), nationality, assigned sex at birth, and age. These variables were assessed to describe the sample (see the Sample section for the statistics).

$e$ LoriCorps Immersive Body Rating Scale version 1.1 (eLoriCorps-IBRS 1.1). This instrument employed virtual bodies holding a standard anatomical pause see Figures 1 and 2 that show screenshots from the VR-based, mobile app-based and paper-based perspective are slightly distorted compared to reality (e.g., fisheye distortion in the allocentric illustration, and variations in viewpoints in the egocentric perspective). This instrument contains two environments for assessing the allocentric and egocentric perspectives (administered in a random sequence) and a female and male version of each to be used, depending on the sex at birth of the user. A neutral VR environment was also implemented to familiarize participants with the use of the $e$ LoriCorps-IBRS 1.1. In the allocentric perspective environment, participants were immersed in VR facing a line-up of seven virtual bodies and walked around each of them. After examining each virtual body for 40 to 60 seconds (see [47] for a detailed description of the procedure), the participants walked to face the virtual body that best represented their own body (Perceived Body Size-Allo. VR), and then to the virtual body they wanted to look like (Ideal Body Size-Allo. VR). In the egocentric perspective virtual environment, participants looked down at their feet and experienced each of the seven bodies for 40 to 60 seconds (see [47] for a detailed description of the procedure). Participants then transitioned to the virtual body they estimated as best representing their body size (Perceived Body Size-Ego. VR) and to the virtual body they wanted to look like (Ideal Body Size-Ego. VR).

Body Dissatisfaction scores, for the allocentric perspective (i.e., Body Dissatisfaction. VR) and the egocentric perspective (i.e., Body Dissatisfaction-Ego. VR), were calculated from the perceived body size minus the ideal body size. A positive score indicated that the participant desired a thinner body than their perceived body size, and a negative score indicated that the participant desired a larger body than their perceived body size. Scores can range from -6 (i.e., no dissatisfaction) to \pm 6 (i.e., extreme dissatisfaction).

Body Distortion scores were calculated from the actual body size of the participant minus the perceived body size for the allocentric perspective (i.e., Body Distortion-Allo. VR) and the egocentric perspective (i.e., Body Distortion-Ego. VR). A positive score indicated that the participant perceived their body as thinner than their actual BMI, while a negative score meant that the participant perceived their body as bigger than their actual BMI. Scores can range from 0 (i.e., no distortion) to \pm 6 (i.e., extreme distortion). 


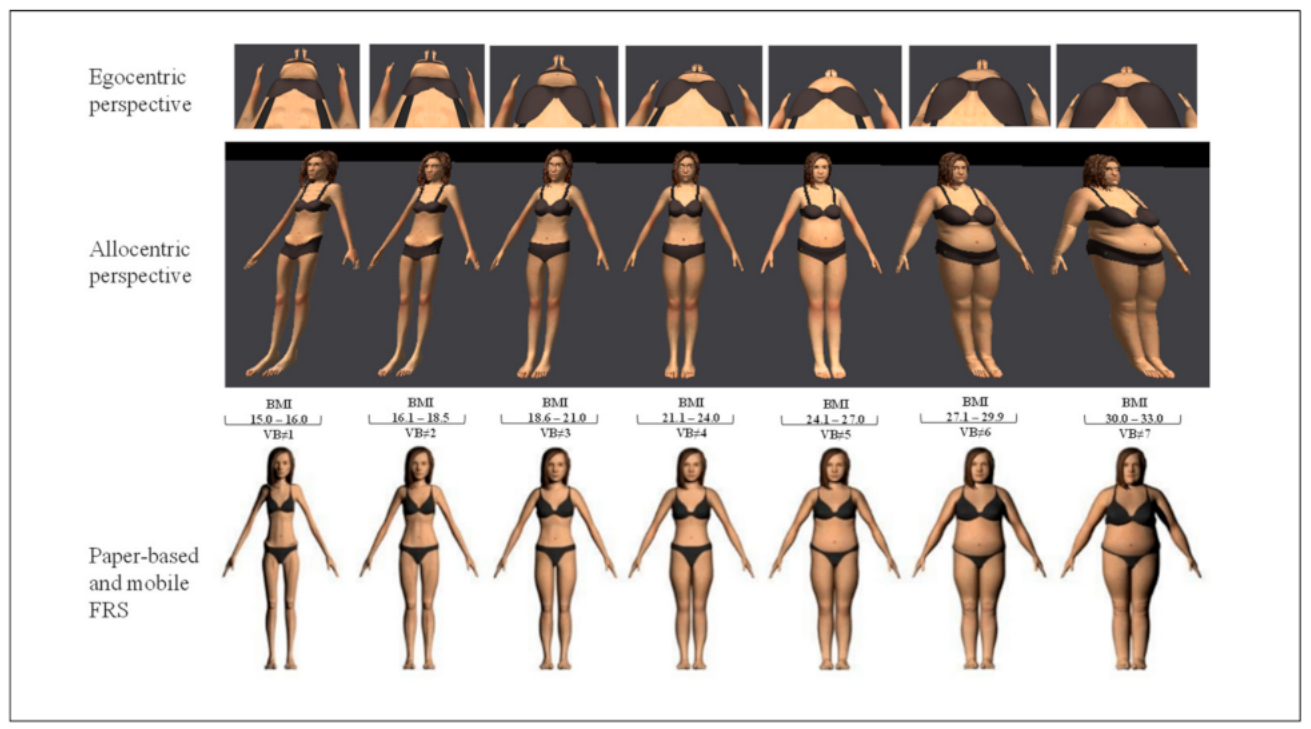

Figure 1. Representation of the allocentric and egocentric perspectives of $e$ LoriCorps-IBRS 1.1 used with female participants.

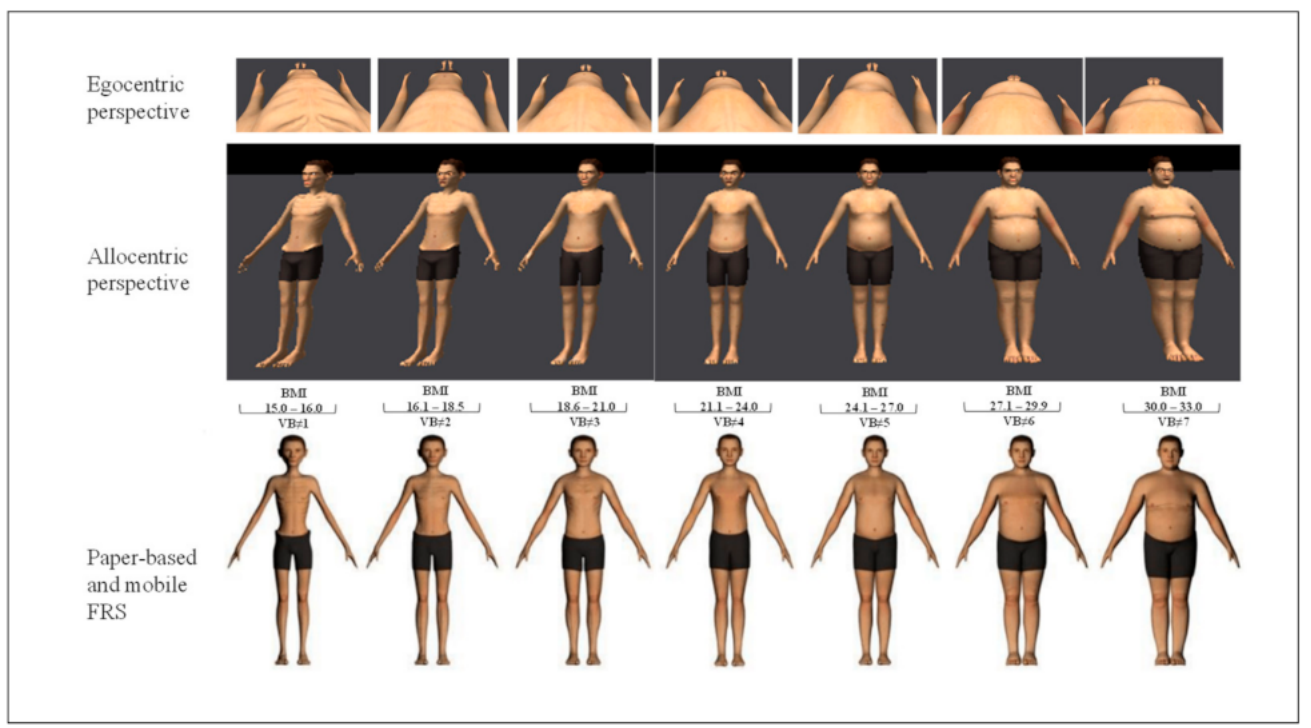

Figure 2. Representation of the allocentric and egocentric perspectives of $e$ LoriCorps-IBRS 1.1 used with male participants.

eLoriCorps mobile app based Body Rating Scale (eLoriCorps-IBRS 1.1-Mobile; developed by Loricorps' team, at Université du Québec à Trois-Rivières, Quebec, CANADA). This instrument employed an app-based FRS with seven virtual bodies on a visual analog scale, showing a female or male version of each depending on the sex at birth of the user. A cell phone with the mobile app already open was given to the participant. Then, they were asked to observe the virtual bodies and select the one best representing their body size (Perceived Body Size-Allo. mobile) and the one they wanted to look like (Ideal Body Size-Allo. mobile). All scores range from 0 to \pm 6 . Body Dissatisfaction scores for the mobile app (i.e., Body Dissatisfaction-Allo. mobile) were calculated from the perceived body size minus the ideal body size. Body Distortion scores were calculated for the mobile app (i.e., Body Distortion-Allo. mobile) from the actual BMI of the participant minus the BMI of the perceived body size. Scores can range from 0 (i.e., not dissatisfied) to \pm 6 (i.e., extremely dissatisfied). 
Figure rating scale. The FRS [59] is a paper-based questionnaire consisting of seven body figures, presented in an allocentric perspective, that increase in size from thinnest to largest, numbered from 1 to 7 . Participants were asked to circle their Perceived Body size and their Ideal Body size. Body Dissatisfaction (i.e., Body Dissatisfaction-Paperbased FRS) and Body Distortion (i.e., Perceptual Body Distortion-Paper-based FRS) scores were calculated as recommended by the authors [59], which is similar to the procedures employed for the eLoriCorps-IBRS 1.1.

Eating Disorder Inventory. The French very short version of the Eating Disorder InventoryAdolescent version (EDI-A) represents a 16-item multidimensional self-report questionnaire that assesses symptoms of eating disorders in adolescent populations [60]. This instrument was validated among a community sample of female and male adolescents [60]. The questionnaire comprises eight subscales (i.e., Drive for Thinness, Bulimia, Body Dissatisfaction corresponding to the ED-Symptom Index as well as Ineffectiveness, Perfectionism, Interpersonal Distrust, Interoceptive Awareness and Maturity Fears corresponding to the ED-PersonalityTrait Index) and is based on a Likert scale from 0 "not at all" to 5 "extremely". The EDI total score, index score and each subscale total scores were reported. In our sample, Cronbach's alpha was 0.78, showing excellent internal consistency [61].

Social Physique Anxiety Scale. The Social Physique Anxiety Scale (SPAS-12) [37], validated in French by Maïano et al. [62], is a 12-item self-report scale developed to assess the degree to which people become anxious when others observe or evaluate their physiques. This questionnaire was validated among a community sample of male and female adolescents [62]. The instrument is based on a Likert scale from 1 "not at all" to 5 "extremely". In our sample, Cronbach's alpha was 0.92, illustrating excellent internal consistency [61].

Body Image Avoidance Questionnaire. The Body Image Avoidance Questionnaire (BIAQ-A) [36], Adolescents French version of Maïano et al. [63], is a 19-item self-report measure of behavioral avoidance of situations and experiences that could provoke concerns about one's own physical appearance, such as social activities that involve eating or wearing tight-fitting clothes. The questionnaire was validated among a community sample of female and male adolescents [63] and is characterized by four subscales: clothing (i.e., wearing clothes that hide one's own body), social activities (i.e., avoiding social activities that imply eating or that draw attention to one's own body), eating restraint, and grooming/weighing (i.e., checking behaviors such as weighing or scrutinizing one's own body in the mirror). Items can score from 0 "never" to 5 "always". The questionnaire's internal consistency reliability (in the present study: Cronbach $\alpha=0.63$ ) is consistent with what was reported in other studies (e.g., Cronbach $\alpha$ ranged between 0.64 and 0.89 [64]).

Simulator Sickness Questionnaire. The French version of the Simulator Sickness Questionnaire [65] measures cybersickness or the presence of physiological discomfort during VR immersion. The 16-item questionnaire employs a Likert scale from 0 "none" to 3 "severe". In our sample, Cronbach's alpha was 0.84, indicating excellent internal consistency [61]. SSQ total raw scores were calculated, as recommended by Bouchard et al. [66].

\subsection{Procedure}

The study protocol was approved beforehand by the ethics committees of the Université du Québec à Trois-Rivières (UQTR; CER-21-280-08-02.24). Parents were informed of the study but their consent was not required. In Quebec, the participation of teenagers aged 14 and over does not require parental consent. The study did not include any compensation since it was integrated into the community's regular activities. Participants were recruited from 285 schools in Quebec. Students aged 14 and older were informed about the study directly in their classes, by the teacher, or during FitSpirit physical activity (visit the website www.fitspirit.ca for further information; Leduc et al. [67]). They were free to participate or not and were required to speak with the project contact representative of their school or FitSpirit-referent-person if they expressed interest in participating. The research assistants responsible for collecting the data in schools were Ph.D. students. The 
height and weight of the participants were measured without shoes. Then, all participants completed the paper-based questionnaires (EDI-A, BIAQ, SPAS) and the paper-based FRS. Next, the $e$ LoriCorps-IBRS 1.1 and $e$ LoriCorps-IBRS 1.1-Mobile versions were administered, randomly, by the experimenter. Before administering the test, the experimenter explained the procedure to participants and provided them with bottled water (in case they felt ill). Participants were informed that some cybersickness could occur and were encouraged to mention it if it happened. After the experiment with the $e$ LoriCorps-IBRS 1.1, the Simulator Sickness Questionnaire was administered to all participants. Finally, the participants were invited to document their immersive experience through four open questions related to their impressions and feelings towards the immersions.

\subsection{Statistical Analysis}

In comprehensive and comparative perspectives, the data analysis is based on virtual body score for (i) actual body size and (ii) perceived and ideal body size measures. For the actual body size measure, see Figures 1 and 2 for the correspondence between VB and BMI. For perceived and ideal body size measures, virtual body-VB\#1 corresponds to visual analog scale (VAS) less than or equal to $14 \%$; virtual body VB\#2 corresponds to VAS between over $14 \%$ and equal to or less than $29 \%$; virtual body VB\#3 corresponds to VAS between over $29 \%$ and equal to or less than $43 \%$; virtual body VB\#4 corresponds to VAS between over $43 \%$ and equal to or less than $57 \%$ : virtual body VB\#5 corresponds to VAS over $57 \%$ and equal to or less than $71 \%$; virtual body VB\#6 corresponds to VAS over $71 \%$ and equal to or less than $86 \%$; virtual body VB\#7 corresponds to VAS over $86 \%$. To document the potential impact of the participant's sex at birth on the results, all statistical analyses were also performed separately for females and males. The results did not differ when analyzed separately for each sex (i.e., significant differences remained significant, and nonsignificant differences remained non-significant). Therefore, to maximize statistical power, results for the aggregated sample were reported (results analyzed by sex are available upon request). Parametric variables were represented as mean \pm standard deviation (SD). The statistical analysis was performed using Stata 16.1 software. Pearson correlation was performed to analyze the relationship between questionnaires and body dissatisfaction and body distortion. Since multiple analyses were performed in this study, a correction for the inflation of Type 1 error was applied to the alpha level to consider results of objectives 1 (O.1) and $2(\mathrm{O} .2)$ as statistically significant. A Bonferroni correction was applied familywise for each component of BIDs (i.e., for Perceived Body Size score, Ideal Body Size score, Body Dissatisfaction score, and Body Distortion score), resulting in a $p$-value lower than $0.008(0.05 / 6)$ for Pearson correlations. Regarding BMI, two outliers were found in the data. Since raw BMI data were not used in the analysis (only used to calculate the body distortion), the potential effect of the two outliers on the results became neutralized. Other data were normally distributed. An a priori power analysis was conducted using $G^{*}$ Power3 using a two-tailed test, a medium effect size $(d=0.50)$, and an alpha of 0.05 . Result showed that a total sample of 29 participants was required to achieve a power of 0.80 [68].

\section{Results}

Descriptive statistics on the main measures are reported in Table 1.

Analyses for the convergent and discriminant validity are reported in Table 2. Results revealed almost all correlations were statistically significant, and the application of a strict Bonferroni correction did not strongly influence the findings. The significance level must also be interpreted in the context of a large sample, hence focusing more on the strength of the correlations than on the significance levels. 
Table 1. Descriptive statistics.

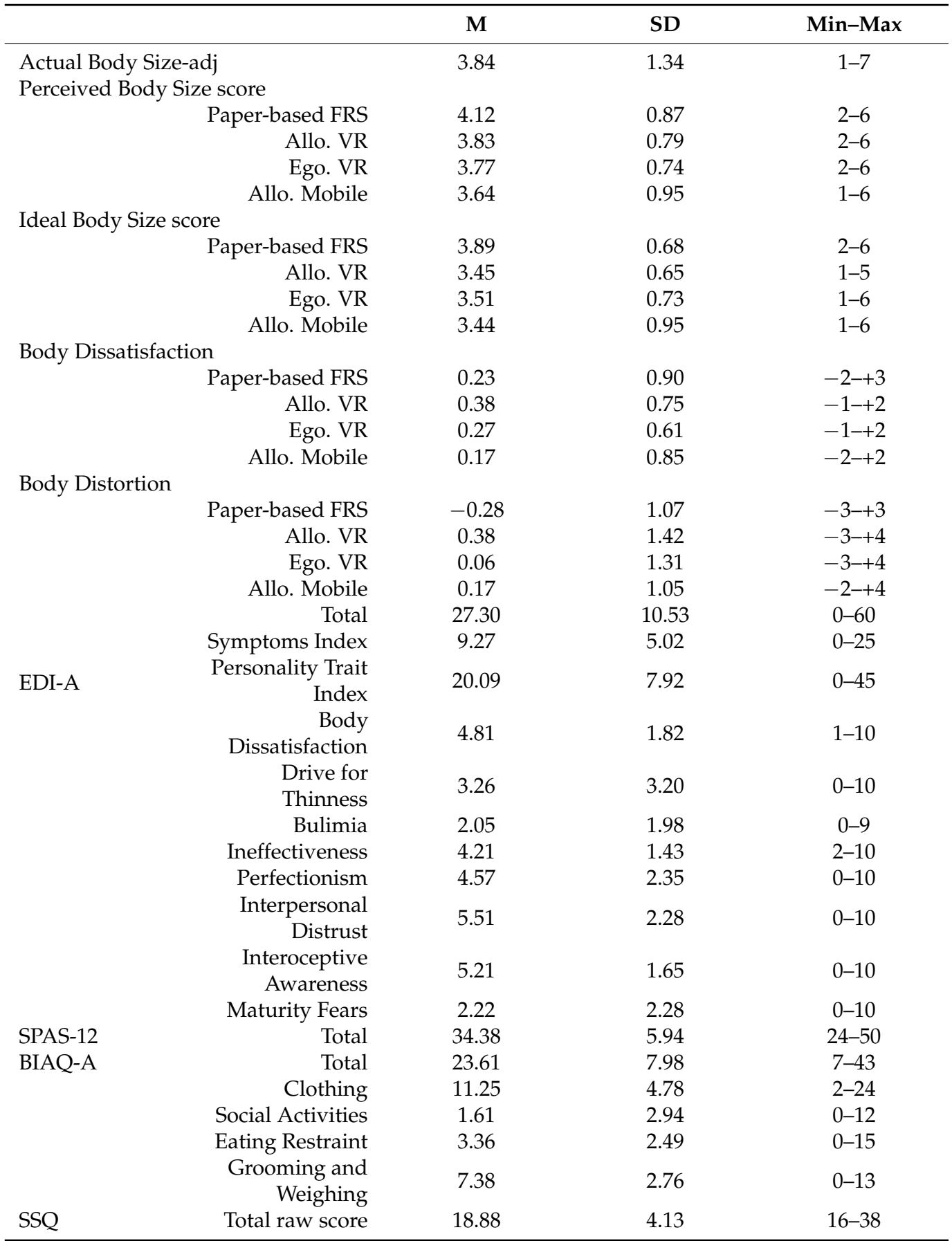

Note. BMI: Body Mass Index; Paper-based FRS: allocentric paper-based Figure Rating Scale; Allo. VR: Allocentric perspective from the $e$ LoriCorps-IBRS 1.1; Ego VR: Egocentric perspective from the $e$ LoriCorps-IBRS 1.1; Allo. Mobile: Allocentric perspective from the $e$ LoriCorps-IBRS 1.1-Mobile; EDI-A: Eating Disorder Inventory-Adolescent version; SPAS-12: Social Physique Anxiety Scale; BIAQ-A: Body Image Avoidance Questionnaire-Adolescent version; SSQ: Simulator Sickness Questionnaire.

The convergent validity of the $e$ LoriCorps-IBRS 1.1-Mobile and the FRS allocentric perspective assessments of body image (O.1) was good (mean $r=0.71$, ps $<0.000$ ) for perceived body size and body distortion. Correlations were still significant, but lower (mean $r=0.53$, $p s<0.000$ ) for ideal body size and for body dissatisfaction. Correlations between the allocentric VR and mobile versions of the $e$ LoriCorps-IBRS 1.1 were strong for perceived body size estimation and body distortion (mean $r=0.73$, $p s<0.000$ ), and lower 
for ideal body size estimation and body dissatisfaction (mean $r=0.49$, ps $<0.000$ ), and thus consistent with patterns observed with the FRS.

Table 2. Convergent and discriminant validity in adolescents, assessed by Pearson correlations for each component of BIDs between the allocentric perspective (paper, virtual reality, mobile application) and egocentric perspective (virtual reality by the $e$ LoriCorps-IBRS 1.1) assessments.

\begin{tabular}{|c|c|c|}
\hline & Pearson Correlation & $p$-Value \\
\hline \multicolumn{3}{|l|}{ Perceived Body Size score } \\
\hline Paper-based FRS vs. Allo. VR & 0.73 & $<0.008 *$ \\
\hline Paper-based vs. Ego. VR & 0.45 & $<0.008$ * \\
\hline Allo. VR vs. Ego. VR & 0.49 & $<0.008 *$ \\
\hline Paper-based FRS vs. Allo. Mobile & 0.66 & $<0.008$ * \\
\hline Allo Mobile vs. Allo. VR & 0.72 & $<0.008$ * \\
\hline Allo Mobile vs. Ego. VR & 0.32 & $0.003 *$ \\
\hline \multicolumn{3}{|l|}{ Ideal Body Size score } \\
\hline Paper-based FRS vs. Allo. VR & 0.53 & $<0.008$ * \\
\hline Paper-based vs. Ego. VR & 0.20 & 0.06 \\
\hline Allo. VR vs. Ego. VR & 0.29 & $<0.008$ * \\
\hline Paper-based FRS vs. Allo. Mobile & 0.48 & $<0.008 *$ \\
\hline Allo. Mobile vs. Allo. VR & 0.40 & $<0.008$ * \\
\hline Allo. Mobile vs. Ego. VR & 0.08 & 0.44 \\
\hline \multicolumn{3}{|l|}{ Body Dissatisfaction score } \\
\hline Paper-based FRS vs. Allo. VR & 0.68 & $<0.008$ * \\
\hline Paper-based vs. Ego. VR & 0.46 & $<0.008$ * \\
\hline Allo. VR vs. Ego. VR & 0.47 & $<0.008 *$ \\
\hline Paper-based FRS vs. Allo. Mobile & 0.58 & $<0.008$ * \\
\hline Allo. Mobile vs. Allo. VR & 0.58 & $<0.008$ * \\
\hline Allo. Mobile vs. Ego. VR & 0.24 & 0.025 \\
\hline \multicolumn{3}{|l|}{ Body Distortion score } \\
\hline Paper-based FRS vs. Allo. VR & 0.74 & $<0.008 *$ \\
\hline Paper-based vs. Ego. VR & 0.76 & $<0.008$ * \\
\hline Allo. VR vs. Ego. VR & 0.82 & $<0.008$ * \\
\hline Paper-based FRS vs. Allo. Mobile & 0.75 & $<0.008$ * \\
\hline Allo. Mobile vs. Allo. VR & 0.73 & $<0.008$ * \\
\hline Allo. Mobile vs. Ego. VR & 0.67 & $<0.008 *$ \\
\hline
\end{tabular}

Note. Paper-based FRS: allocentric paper-based Figure Rating Scale; Allo. VR: Allocentric perspective from the $e$ LoriCorps-IBRS 1.1; Ego VR: Egocentric perspective from the $e$ LoriCorps-IBRS 1.1; Allo. Mobile: Allocentric perspective from $e$ LoriCorps-IBRS 1.1-Mobile. ${ }^{*} p<0.008$.

The discriminant validity of the egocentric perspective from the eLoriCorps-IBRS 1.1 (O.2) in this adolescent sample was supported by low correlations between assessments from the allocentric perspective of the paper based-FRS vs. the egocentric perspective of the $e$ LoriCorps-IBRS 1.1 for perceived body size $(r=0.45, p<0.008)$, and body dissatisfaction $(r=0.46, p<0.008)$, and by a non-significant correlation regarding the assessment of ideal body size $(p=0.06)$. Contrary to expectations, a higher correlation was identified for the assessment of body distortion $(r=0.76, p<0.008)$. The same pattern of results was discovered for the correlations between the allocentric assessments vs. the egocentric ones of the eLoriCorps-IBRS 1.1, except for body distortion $(r=0.82, p<0.008)$. Concerning the allocentric perspective of $e$ LoriCorps-IBRS 1.1-Mobile, results showed lowest correlations with the egocentric perspective of the $e$ LoriCorps-IBRS 1.1 for perceived body size $(r=0.31$, $p=0.003)$, and by a non-significant correlation regarding the assessment of ideal body size $(p=0.44)$, and body dissatisfaction $(p=0.025)$. As previously mentioned, a higher correlation was identified for the assessment of body distortion $(r=0.67, p<0.008)$. To show that correlations in favor of discriminant validity are indeed different from those in favor of convergent validity, correlation coefficients were compared with document statistical differences (Field, 2018). Correlations between the egocentric VR-based perspective and the allocentric VR-based perspective were significantly lower than the correlations between the allocentric-VR based perspective and the allocentric paper-based perspective for perceived body size $(p<0.01)$, ideal body size $(0.02<p<0.05)$ and body dissatisfaction $(p<0.01)$. Regarding body distortion, the correlation between the egocentric VR-based perspective and the allocentric VR-based perspective was significantly higher than the 
correlation between the allocentric-VR based perspective and the allocentric paper-based perspective $(0.02<p<0.05)$. Correlations between the egocentric VR-based perspective and the allocentric paper-based FRS were significantly lower $(p s<0.01)$ than correlations between the allocentric VR-based perspective and the allocentric paper-based FRS for perceived body size, ideal body size and body dissatisfaction. The correlation between the egocentric VR-based perspective and the allocentric paper-based FRS was not significantly different $(p>0.20)$ from the correlation between the allocentric VR-based and the allocentric paper-based FRS for body distortion. Correlations between the egocentric VR-based and the allocentric mobile-based perspectives were significantly lower $(p s<0.01)$ than correlations between the allocentric VR-based and the allocentric mobile-based perspectives for perceived body size, ideal body size and body dissatisfaction. The correlation between the egocentric VR-based perspective and the allocentric mobile-based perspective was not significantly different $(0.10<p<0.20)$ from the correlation between the allocentric VR-based perspective and the allocentric mobile-based perspective for body distortion. In summary, the discriminant validity of the egocentric perspective from the eLoriCorps-IBRS 1.1 is particularly confirmed with the allocentric perspective of the technology-based method (eLoriCorps-IBRS 1.1 and $e$ LoriCorps-IBRS 1.1-Mobile) to measure ideal body size.

Exploratory discriminant validity analyses display significant correlations between body dissatisfaction and body distortion scores and external variables (see Tables 3 and 4). The allocentric $e$ LoriCorps-IBRS 1.1 and $e$ LoriCorps-IBRS 1.1-Mobile assessments of body dissatisfaction were significantly related to the total score of the BIAQ. Furthermore, both the mobile- and VR-based allocentric body distortion assessments were significantly correlated with the total score of the EDI-A, the Personality Index and Symptoms Index, whereas the total score of the BIAQ was significantly associated only with the VR-based allocentric body distortion assessment. The SPAS-12 was not significantly associated with body dissatisfaction or with body distortion. Body dissatisfaction and body distortion measured in the allocentric paper-based FRS were not significantly associated with any attitudinal-affective-cognitive variables associated with BIDs.

Table 3. Pearson correlations (with exact $p$ values in brackets) for the total of questionnaires measuring components of BID and three rating scales administered to adolescents: a paper-based FRS, the $e$ LoriCorps-IBRS 1.1 allocentric and egocentric perspectives, and the $e$ LoriCorps-IBRS 1.1-Mobile allocentric perspective.

\begin{tabular}{|c|c|c|c|c|c|}
\hline & EDI-A & EDI-A-S-Index & EDI-A-P-Index & SPAS-12 & BIAQ-A \\
\hline \multicolumn{6}{|l|}{ Body Dissatisfaction score } \\
\hline \multirow{2}{*}{ Paper-based FRS } & 0.12 & 0.11 & 0.15 & 0.19 & 0.15 \\
\hline & $(0.25)$ & $(0.30)$ & $(0.16)$ & $(0.07)$ & $(0.15)$ \\
\hline \multirow{2}{*}{ Allo. VR } & 0.09 & 0.10 & 0.13 & 0.15 & 0.23 \\
\hline & $(0.38)$ & $(0.31)$ & $(0.21)$ & $(0.17)$ & $\left(0.03^{*}\right)$ \\
\hline \multirow{2}{*}{ Ego. VR } & 0.03 & 0.001 & 0.04 & 0.10 & 0.05 \\
\hline & $(0.79)$ & $(0.99)$ & $(0.67)$ & $(0.371)$ & $(0.63)$ \\
\hline \multirow{2}{*}{ Allo. Mobile } & -0.01 & 0.05 & 0.02 & 0.08 & 0.25 \\
\hline & $(0.93)$ & $(0.66)$ & $(0.82)$ & $(0.45)$ & $(0.02 *)$ \\
\hline \multicolumn{6}{|l|}{ Body Distortion score } \\
\hline \multirow{2}{*}{ Paper-based FRS } & 0.10 & 0.16 & 0.10 & -0.03 & 0.16 \\
\hline & $(0.36)$ & $(0.12)$ & $(0.34)$ & $(0.79)$ & $(0.14)$ \\
\hline \multirow{2}{*}{ Allo. VR } & 0.22 & 0.23 & 0.24 & 0.05 & 0.23 \\
\hline & $(0.04 *)$ & $\left(0.03^{*}\right)$ & $(0.02 *)$ & $(0.66)$ & $\left(0.03^{*}\right)$ \\
\hline \multirow{2}{*}{ Ego. VR } & 0.06 & 0.07 & 0.15 & -0.008 & 0.19 \\
\hline & $(0.59)$ & $(0.47)$ & $(0.16)$ & $(0.94)$ & $(0.08)$ \\
\hline \multirow{2}{*}{ Allo. Mobile } & 0.28 & 0.30 & 0.13 & -0.014 & 0.157 \\
\hline & $\left(0.01^{* *}\right)$ & $\left(0.005^{* *}\right)$ & $(0.21)$ & $(0.90)$ & $(0.16)$ \\
\hline
\end{tabular}


Regarding the specific correlations between the EDI-A and BIAQ subscales and body dissatisfaction and body distortion, the allocentric eLoriCorps-IBRS 1.1 body dissatisfaction assessment was significantly correlated to maturity fear and eating restraint, whereas the allocentric $e$ LoriCorps-IBRS 1.1-Mobile body dissatisfaction assessment was significantly associated with maturity fear, covering up the body with clothes that hide one's own body, and avoidance of social activities that could provoke concerns about one's own physical appearance. Body dissatisfaction measured in the egocentric VR-based perspective was negatively associated with interoceptive awareness. Eating restraint significantly correlated with all measures of body distortion, whereas avoidance of social activities was significantly related to body distortion measured in the allocentric VR-based perspective. Finally, maturity fear was significantly related to body distortion, measured in the allocentric paperbased and VR-based condition and in the egocentric VR-based condition. The relationships were medium with correlations ranging from 0.21 to 0.29 [69]. These effect sizes appear to be generally lower for body distortion than for the body dissatisfaction scores.

Table 4. Pearson's correlations (with exact $p$ values in brackets) for the subscales of questionnaires measuring components of BIDs and three rating scales administered to adolescents: a paper-based FRS, the $e$ LoriCorps-IBRS 1.1 allocentric and egocentric perspectives, and the $e$ LoriCorps-IBRS 1.1Mobile allocentric perspective.

\begin{tabular}{|c|c|c|c|c|c|c|c|c|}
\hline & \multicolumn{4}{|c|}{ Body Dissatisfaction } & \multicolumn{4}{|c|}{ Body Distortion } \\
\hline & $\begin{array}{c}\text { Paper- } \\
\text { FRS }\end{array}$ & $\begin{array}{l}\text { Allo. } \\
\text { VR }\end{array}$ & Ego. VR & Allo. M. & $\begin{array}{l}\text { Paper- } \\
\text { FRS }\end{array}$ & $\begin{array}{l}\text { Allo. } \\
\text { VR }\end{array}$ & Ego. VR & Allo. $\mathrm{M}$. \\
\hline \multirow{2}{*}{ EDI-A-BD } & 0.03 & 0.09 & 0.02 & -0.05 & 0.11 & 0.22 & 0.09 & 0.21 \\
\hline & $(0.82)$ & (0.39) & $(0.89)$ & $(0.64)$ & $(0.30)$ & $(0.04 *)$ & $(0.40)$ & $(0.07)$ \\
\hline \multirow{2}{*}{ EDI-A-DT } & 0.12 & 0.18 & -0.02 & 0.13 & 0.18 & 0.23 & 0.09 & 0.17 \\
\hline & $(0.26)$ & $(0.09)$ & $(0.86)$ & $(0.26)$ & $(0.01)$ & $(0.04 *)$ & $(0.44)$ & $(0.13)$ \\
\hline \multirow{2}{*}{ EDI-A-BU } & -0.17 & -0.14 & -0.09 & 0.11 & 0.01 & -0.11 & -0.001 & -0.03 \\
\hline & $(0.12)$ & $(0.21)$ & $(0.43)$ & $(0.34)$ & $(0.91)$ & $(0.32)$ & $(0.99)$ & $(0.77)$ \\
\hline \multirow{2}{*}{ EDI-A-IN } & -0.008 & 0.02 & -0.08 & 0.03 & 0.16 & 0.19 & 0.18 & 0.24 \\
\hline & $(0.94)$ & $(0.84)$ & $(0.47)$ & $(0.79)$ & $(0.14)$ & $(0.07)$ & $(0.10)$ & $\left(0.03^{*}\right)$ \\
\hline \multirow{2}{*}{ EDI-A-PE } & -0.02 & 0.001 & 0.003 & 0.07 & 0.08 & 0.11 & 0.10 & -0.06 \\
\hline & $(0.82)$ & (0.99) & $(0.98)$ & $(0.51)$ & $(0.45)$ & $(0.33)$ & $(0.35)$ & $(0.62)$ \\
\hline \multirow{2}{*}{ EDI-A-ID } & 0.001 & 0.11 & 0.19 & -0.006 & -0.03 & 0.06 & 0.002 & -0.02 \\
\hline & $(0.99)$ & $(0.29)$ & $(0.07)$ & $(0.96)$ & $(0.77)$ & $(0.57)$ & (0.99) & $(0.85)$ \\
\hline \multirow{2}{*}{ EDI-A-IA } & -0.05 & -0.02 & -0.22 & -0.05 & -0.09 & -0.02 & -0.10 & -0.04 \\
\hline & $(0.65)$ & $(0.87)$ & $(0.04 *)$ & $(0.68)$ & $(0.42)$ & $(0.82)$ & $(0.35)$ & $(0.70)$ \\
\hline \multirow{2}{*}{ EDI-A-MF } & 0.17 & 0.27 & 0.01 & 0.28 & 0.27 & 0.35 & 0.27 & 0.20 \\
\hline & 0.10 & $(0.01 *)$ & $(0.90)$ & $(0.01 *)$ & $(0.01 *)$ & $\left(0.001^{* *}\right)$ & $(0.01 *)$ & $(0.08)$ \\
\hline \multirow{2}{*}{ BIAQ-C } & 0.150 & 0.11 & 0.12 & 0.24 & 0.009 & 0.05 & 0.009 & -0.04 \\
\hline & $(0.17)$ & $(0.30)$ & $(0.25)$ & $(0.03 *)$ & $(0.93)$ & $(0.64)$ & (0.93) & $(0.73)$ \\
\hline \multirow{2}{*}{ BIAQ-S } & 0.11 & 0.20 & -0.04 & 0.24 & 0.14 & 0.24 & 0.18 & 0.12 \\
\hline & $(0.31)$ & $(0.06)$ & $(0.69)$ & $(0.03 *)$ & $(0.21)$ & $(0.02 *)$ & (0.09) & $(0.28)$ \\
\hline \multirow{2}{*}{ BIAQ-E } & 0.15 & 0.31 & 0.09 & 0.13 & 0.29 & 0.36 & 0.26 & 0.25 \\
\hline & $(0.16)$ & $\left(0.003^{* *}\right)$ & $(0.36)$ & $(0.25)$ & $\left(0.007^{* *}\right)$ & $\left(0.001^{* *}\right)$ & $(0.01 *)$ & $(0.02 *)$ \\
\hline \multirow{2}{*}{ BIAQ-G } & -0.03 & -0.02 & -0.11 & -0.07 & 0.02 & 0.004 & 0.07 & 0.17 \\
\hline & $(0.81)$ & $(0.82)$ & $(0.32)$ & $(0.52)$ & $(0.84)$ & $(0.97)$ & $(0.55)$ & $(0.12)$ \\
\hline
\end{tabular}

Note. EDI-A: Eating Disorder Inventory Scale; BD: Body Dissatisfaction Subscale; DT: Drive for Thinness Subscale; BU: Bulimia Subscale; IN: Infectiveness Subscale; PE: Perfectionism Subscale; ID: Interpersonal Distrust Subscale; IA: Interoceptive Awareness Subscale; MF: Maturity Fear Subscale; BIAQ-A: Body Image Avoidance Questionnaire; C: Clothing Subscale; S: Social Activity Subscale; E: Eating Restraint Subscale; G: Grooming and Weighing Subscale; Paper-FRS: paper Figure Rating Scale; Allo. VR: Allocentric perspective from the $e$ LoriCorpsIBRS 1.1; Ego VR: Egocentric perspective from the $e$ LoriCorps-IBRS 1.1; Allo. Mobile: Allocentric perspective from the $e$ LoriCorps-IBRS 1.1-Mobile. ${ }^{*} p<0.05 ;{ }^{* *} p<0.01$.

\section{Discussion}

The current study examined (O.1) the convergent validity between the allocentricbased assessments (paper-based FRS, eLoriCorps-IBRS 1.1 and $e$ LoriCorps-IBRS 1.1-Mobile) of BIDs and (O.2) the discriminant validity of the egocentric perspective (measured with the VR-based $e$ LoriCorps-IBRS 1.1) versus the allocentric-based assessments (paper-based FRS, $e$ LoriCorps-IBRS 1.1 and $e$ LoriCorps-IBRS 1.1-Mobile) of BIDs in a community sample of adolescents. Moderate convergent validity was discovered between the allocentric (pa- 
per, VR, mobile application) assessments of body dissatisfaction and body distortion. As expected, the egocentric VR perspective yielded results that were not strongly correlated with the allocentric (paper, VR), and not significantly correlated with the allocentric mobilebased measures of body dissatisfaction. However, correlations did not significantly differ regarding body distortion. Concerning the exploratory discriminant analyses, the different strengths of relationships between dimensions of BIDs in egocentric and allocentric perspectives and other attitudinal-affective-cognitive variables associated with BIDs, such as eating disorders symptoms (EDI-A), body image avoidance (BIAQ-A), and social physique anxiety (SPAS-12), are further discussed in the following paragraphs. Adolescents who participated in this study reported marginal dissatisfaction about their body size. Participants tended to slightly overestimate their body size when using traditional paper-based FRS, and to slightly underestimate it when using eLoriCorps-IBRS 1.1-Mobile. Participants tended to select an ideal body closer to their actual body size when using the paper-based FRS than when using a technology-based instrument. The overall results of convergent and discriminant validity tended to reveal two main observations. First, it must be noted that for all body distortion measures, participants' means were close to zero and standard deviations represented the highest of all measures. This observation is consistent with findings from other authors who stated that body distortion appears primarily in clinical populations rather than in the general population [21,70].

\subsection{Allocentric Convergent and Egocentric Discriminant Validity of the eLoriCorps-IBRS 1.1 in Adolescents}

Convergent validity (O.1) between the allocentric perspective of the $e$ LoriCorps-IBRS 1.1 and the paper-based FRS was confirmed when assessing perceived body size, ideal body size, body dissatisfaction, and body distortion. These results obtained from a community sample of adolescents mirror the results that the authors found when validating the first version of the $e$ LoriCorps (i.e., $e$ LoriCorps-IBRS 1.0) among a community sample of adults [47], and were in line with results from Fisher et al. [71], who did not observe a significant difference in assessing body distortion between a paper-based FRS and a VR-based FRS. Convergent validity was found between the $e$ LoriCorps-IBRS 1.1-Mobile and both the allocentric perspective of the eLoriCorps-IBRS 1.1 and of the paper-based FRS for all body image-related variables (i.e., perceived body size assessment, ideal body size assessment, body dissatisfaction, body distortion). These results are quite encouraging when researchers and clinicians work with adolescents. The use of the mobile application eLoriCorps-IBRS 1.1-Mobile can offer a more portable and acceptable way to assess the allocentric perspective of body image-related variables among youth populations. These mobile-based methods might be more appealing for teenagers, who already integrate cell phone usage in their daily routine to accomplish different tasks (e.g., searching for information, interacting with peers, watching videos and playing games), and particularly when implementing the cognitive (allocentric) and perceptual (egocentric) training of BIDs.

Discriminant validity (O.2) between the egocentric- and allocentric-based assessments was confirmed for all body image-related variables with the exception of body distortion. More precisely, results seem to indicate that assessing ideal body size, perceived body size and body size dissatisfaction in an egocentric perspective is somewhat different than assessing the same phenomena in an allocentric perspective, both in VR-based and mobilebased assessments and by using paper-based FRS. Similar results were obtained by the authors among a community sample of adults [47].

\subsection{Egocentric-Perceptual-Sensory-Affective Construction: The Hidden and Deepest Part of the "BIDs Iceberg"?}

Experiencing the body in an egocentric perspective might be quite different than experiencing the body from a "third-person" point of view. Indeed, the body is experienced both as an object (i.e., third-person allocentric perspective) in the physical world, and as a subject (i.e., first-person egocentric perspective), on a daily basis. This is particularly true during the "famous storming-adolescent-period" which constitutes a real challenge due 
to both the physical and psychological upheaval [72]. The "object-body", theorized by Foucault (1975) as "Body-machine", is experienced, judged, and observed by others only in an allocentric perspective, and vice versa. The allocentric representation of one's own body is constantly compared with the allocentric perspective of others' bodies. The internalization of an observer's point of view on one's own body is called "self-objectification" [73], which implies the internalization of an objectified cultural ideal of beauty. In Canadian society, the youth population (as our sample) is vulnerable to the widespread societal messaging prevalent in Western cultures, which favors thin, muscular bodies [74]. The fear to change one's own body was highlighted by our results on the correlation between BIDs and maturity fears. A mechanism of constant body surveillance or systematic monitoring of one's own body is triggered. The discrepancy between one's body-as-an-object and this ideal-cultural-prescription, can provoke body dissatisfaction, body shame, social physique anxiety, body checking, and body avoidance, which are all recognized predictors for the development of eating disorders [55,75-79]. While the body as-an-object could be more exposed to inter-individual comparison in a (Western) cultural context, the egocentric construction of the body-as-a-subject, could be exposed to intra-individual comparison in one's own ecological daily context (mood, physiological hunger, and satiety sensations, etc.). Indeed, as theorized by the Allocentric Lock Theory, the egocentric perspective involves somatoperceptions, more precisely interoceptive percepts about the nature and state of the body [51-56]. Thus, the perception of the body from a first-person point of view could be influenced by one's own interoceptive awareness, which refers to the ability to identify, access, understand and respond appropriately to internal bodily signals [80]. More precisely, this subjective perception of sensations arising from inside the body encompasses the proprioceptive experience of body state, the perception of hunger/satiety signals, cardiovascular, respiratory, colorectal and urinary sensations. The results of the present study appear to point in this direction, as a significant negative correlation was identified between the egocentric assessment of body dissatisfaction and interoceptive awareness. However, future studies are required to shed light on this association. An increasing number of studies have been investigating impaired interoceptive awareness in eating disorders (composing the famous EDI measurement) [81], especially among anorexia and bulimia nervosa patients [82]. This suggests that interoceptive awareness disturbances are both a vulnerability and a reinforcing factor of a pathological drive for thinness leading to restrictive eating [34,83-87]. Furthermore, exploring bodily sensations from an egocentric perspective can increase one's own ability to reconnect with internal bodily signals, especially food-related signals (hunger and satiety cues). This echoes two different intervention approaches: (i) yoga allows to bridge the gap between the mind-body experience and enhances the experience of embodiment [88], and (ii) an adaptative nutritional approachintuitive eating [89] — to decrease the negative impacts of restrained eating $[47,87,90,91]$. The intuitive movement (yoga) and eating are employed in the recent prevention and treatment of eating disorders, including binge-eating disorder [92,93]. In conclusion, the egocentric perspective could reflect a perceptual-sensory-affective construction of the body, whereas an allocentric representation could reflect a cognitive-affective-attitudinal construction of the body. Therefore, egocentric- vs allocentric-based body image disturbances become two sides of the same coin.

\subsection{Implications for Innovative Integrative Intervention}

Traditionally, BIDs were assessed through different methods, such as self-reported questionnaires, depictive and metric body size estimation tasks. While body image distortion can be measured only by body size estimation tasks, body dissatisfaction can be measured by either self-reported questionnaires or body size estimation tasks. But, when we are implementing these two evaluative methods, are we sure that we are measuring the same phenomenon? In short, we do not believe so. Body dissatisfaction as measured by well-established self-reported questionnaires was not associated with the same construct assessed by any of the depictive methods used in this study. We could hypothesize that these 
two methods are assessing different shadows of body dissatisfaction. The self-reported questionnaire could be assessing cognitive-attitudinal-affective dimensions of body dissatisfaction [81], whereas through depictive methods it is also possible to reach and explore perceptual-sensory-affective dimensions of body dissatisfaction (i.e., the lived body) [94], and particularly the sensory dimension, owing to embodiment-egocentric perspectives, as they require judgement and evaluation of the physical dimensions of the body.

In preventive and therapeutic implications, this study supports the hypothesis of the self-objectification of the allocentric perspective of the body, which may be more related to phenomena such as avoidance of situations that could trigger concerns about one's own physical appearance, and dysfunctional eating attitudes such as body checking and the drive to achieve thinness. Indeed, in this developmental period and social context, the adolescents' object-body should represent the target content of an eating disorder preventive program [95]. On the other hand, the egocentric body representation could tap into something different from the allocentric perspectives via the perceptual-sensory-affective construction of the body. In the preventive view, the change from allocentric-object-body to egocentric-subject-body could be akin to the change from cultural beauty to inner beauty through the acceptance process. In this case, since the virtual bodies represent the adult body, it may be possible that adolescents of the current study can project themselves more easily in the allocentric perspective, as the representation of their body in mind is related to an interpersonal comparison, which is driven by the internalization of the ideal body. In the egocentric perspective, it may be harder for adolescents to embody the bodies of adults as the egocentric perspective is an intraindividual experience. Targeting BIDs is one of the most difficult preventive and therapeutic goals to achieve, and yet body image remains to be fully understood. Knowing that BIDs are not only related to the cognitive representation of the body in memory, but also to the body perception-driven input from multiple sensory modalities, may allow the development of innovative treatments based on cognitive and perceptual training. These integrated treatments based on holistic body experiences should include multidimensional modalities of BIDs, targeting the body-as-an-object/subject. An increasing number of VR-based interventions focus on targeting different facets of BIDs. However, to the author's knowledge, only one study protocol [96] and a pilot study [97] proposed an intervention targeting both egocentric and allocentric BIDs. In line with recent studies focused on a comprehensive integrated model [98,99], the promising VR-based integrated interventions could address the perceptual-dual-disorders (e.g., eating disorders, body dysmorphic disorder, obsessive-compulsive disorder [100]) by taking into account the current gender-inclusive society [101].

\subsection{Strengths and Limitations in this Current Study Inspiring Further Studies}

There were several strengths to this study combining BIDs among an adolescent sample, in an egocentric-immersive-virtual perspective and an ecological non-immersive mobile application. To our knowledge, the current study constitutes the first validation of a VR-based assessment of BIDs (eLoriCorps-IBRS 1.1) in a community sample of adolescents with a larger sample than previous VR-based studies [102]. Consistent with the recent VR-based validation in a community sample of adults [47], the present study highlights the contribution of an egocentric-immersive-virtual perspective to understand the perceptual-sensory-affective construction of the body image (vs. allocentriccognitive-affective-attitudinal construction). The validation of the mobile application version ( $e$ LoriCorps-IBRS 1.1-Mobile) implies favoring the use of mobile-based assessment methods in self-regulation (preventive intervention) and self-management (therapeutic intervention). The main limitation of this study is the lack of "gold-standard" psychometric instruments to compare with the egocentric VR perspective, which is a novel tool. Another important limitation is that the virtual bodies were more representative of adult bodies than adolescent ones. In order to maintain a certain consistency between the instruments, the adult version of the paper-based FRS was preferred to the adolescent version [103]. This limitation did not seem to have impeded participants from identifying a perceived body 
size that was close to their actual body size. Results of the exploratory analyses should be taken with caution as multiple correlations were performed. Finally, another limitation was the small number of male adolescents participants compared with the number of female adolescents participants. Future studies should include the same proportion of female and male adolescents in order to explore possible gender-based differences.

Future studies should examine the validity of $e$ Loricorps-IBRS 1.1 in an eating disorder sample. More precisely, people with a high BMI may perceive themselves to be larger than the response scale allows, which may lead to a significant response bias, especially in clinical eating disorder populations, including all body weights and shapes. Consequently, it is possible to note that the number of available virtual bodies in the $e$ Loricorps-IBRS continuum might restrict people in their choices. Moving toward a nine virtual body continuum could help limit this bias. In line with this limitation, it could prove necessary to develop and assess virtual bodies that better represent the morphological characteristics of adolescents' bodies. Furthermore, the promising perspectives of self-management interventions that focus on cognitive and perceptual training of BIDs include the development and assessment of a mobile egocentric-based version of the $e$ Loricorps-IBRS 1.1. Indeed, an allocentric and egocentric mobile assessment instrument could be particularly suitable for addressing evaluation and prevention programs within a youth population who develop object-body and subject-body simultaneously. In comprehensive research on self-objectification of the allocentric perspective of the body, the question of whether there are differences when employing adolescent and adult versions of the body continuum should be explored. Indeed, bodily experience, more precisely self-objectification, may play an important role in the development and maintenance of eating disorders [8].

\section{Conclusions}

In conclusion, this validation study provides evidence that the allocentric perspective of $e$ LoriCorps-IBRS 1.1 is a valid tool to assess perceptual-sensory-affective dimensions (egocentric perspective) and cognitive-affective-attitudinal (allocentric perspective) dimensions of BIDs in adolescents. As expected, when comparing it with the validation of the $e$ LoriCorps-IRBS 1.0 in a community sample of adults, the egocentric perspective measured in VR produced different results compared to all measures from the allocentric perspective [paper-based FRS, eLoriCorps (-IBRS 1.1 and -IBRS 1.1-Mobile)] and from cognitive-attitudinal-affective dimensions of BIDs (EDI-A, BIAQ-A and SPAS-12). These differences support the discriminant validity of the egocentric perspective of $e$ LoriCorpsIBRS 1.1 and are consistent with emerging evidence that the egocentric perceptive could reflect a perceptual-sensory-affective construction of BIDs. Allocentric measures appear to be more related to a cognitive-affective-attitudinal construction of BIDs. Moreover, the results support the validity of rating virtual bodies using the $e$ LoriCorps-IBRS 1.1-Mobile, with the potential to be more enticing and to enable ecological momentary assessment. Furthermore, it could be suitable to develop a specific-fitting adolescent virtual body continuum integrated into a mobile egocentric-based version of the $e$ Loricorps-IBRS 1.1 in order to detect, prevent and treat eating disorders.

Author Contributions: Conceptualization, J.M.-B. and S.B.; methodology, J.M.-B. and M.R.; software VR, J.M.-B.; software mobile App, J.M.-B. and F.T.; data collection, J.M.-B., A.C. and F.B.; formal analysis, J.M.-B., S.B., M.R. and G.C.; writing-original draft preparation, J.M.-B., S.B., G.C. and M.O.; writing-review and editing, J.M.-B., G.C., M.O., F.T., F.B., M.R., A.C., N.M., N.R., V.D., M.-E.M. and S.B.; supervision, J.M.-B.; project administration, J.M.-B.; funding acquisition, J.M.-B. All authors have read and agreed to the published version of the manuscript.

Funding: This research was funded by RBC Royal Bank, the Lemaire family, Fond. UQTR-RBC Banque Royale-PI-Loricorps, 2017-2021 (0288007), by the Social Sciences and Humanities Research Council of Canada, 2018-2023 (CRSH-SAVOIR-430-2018-00970-PIE-IC), by the Canada Research Chair in Clinical Cyberpsychology (950-210762), and the Fond de Recherche du Québec-Santé (FRQS; 289006). 
Institutional Review Board Statement: This study was conducted in accordance with the Declaration of Helsinki, and approved by the Ethics Committee of the Université du Québec à Trois-Rivières (UQTR; CER-21-280-08-02.24).

Informed Consent Statement: Informed consent was obtained from all subjects involved in the study.

Data Availability Statement: The data presented in this study are available on request from the corresponding author. The data are not publicly available due to ethical restrictions.

Acknowledgments: Special thanks go to RBC Royal Bank, the Lemaire family, Fondation of Université du Québec à Trois-Rivières, Social Sciences, Humanities Research Council of Canada, Canada Research Chair in Clinical Cyberpsychology, Centre de Recherche de l'Institut Universitaire en Santé Mentale de Montréal, and Fond de Recherche du Québec-Santé whose patronage helped finance the completion of this study. Special thanks to Edouard Blanc for the infographic development of the virtual body constituting the $e$ LoriCorps-IBRS 1.1. Special thanks to Fillactive organization and Chavigny High School for their community support. Thanks to Marlene Menzies comments and revisions on the text and Francisca Bourbeau, Vincent Lemieux and Lola Tournayre for helping with data collection

Conflicts of Interest: Stéphane Bouchard is president of, and owns shares in, Cliniques et Dveloppement In Virtuo, a company that distributes virtual environments, and any conflict of interest is managed under UQO's conflict of interest policy. The other authors declare no conflict of interest.

\section{References}

1. Markey, C.N. Invited commentary: Why body image is important to adolescent development. J. Youth Adolesc. 2010, 39, 1387-1391. [CrossRef] [PubMed]

2. Bucchianeri, M.M.; Arikian, A.J.; Hannan, P.J.; Eisenberg, M.E.; Neumark-Sztainer, D. Body dissatisfaction from adolescence to young adulthood: Findings from a 10-year longitudinal study. Body Image 2013, 10, 1-7. [CrossRef] [PubMed]

3. Neumark-Sztainer, D.; Goeden, C.; Story, M.; Wall, M. Associations between Body Satisfaction and Physical Activity in Adolescents: Implications for Programs Aimed at Preventing a Broad Spectrum of Weight-Related Disorders. Eat. Disord. 2004, 12, 125-137. [CrossRef] [PubMed]

4. Presnell, K.; Bearman, S.K.; Stice, E. Risk factors for body dissatisfaction in adolescent boys and girls: A prospective study. JMIR Form. Res. 2004, 36, 389-401. [CrossRef] [PubMed]

5. Wang, S.B.; Haynos, A.F.; Wall, M.M.; Chen, C.; Eisenberg, M.E.; Neumark-Sztainer, D. Fifteen-Year Prevalence, Trajectories, and Predictors of Body Dissatisfaction from Adolescence to Middle Adulthood. Clin. Psychol. Sci. 2019, 7, 1403-1415. [CrossRef] [PubMed]

6. Dakanalis, A.; Pla-Sanjuanelo, J.; Caslini, M.; Volpato, C.; Riva, G.; Clerici, M.; Carrà, G. Predicting onset and maintenance of men's eating disorders. Int. J. Clin. Health Psychol. 2016, 16, 247-255. [CrossRef] [PubMed]

7. $\quad$ Cazale, L.; Paquette, M.; Bernèche, F. Poids, apparence corporelle et actions à l'égard du poids. L'Enquête Québécoise Sur La St. Des Jeunes Du Second. 2012, 1, 121-148.

8. Dakanalis, A.; Clerici, M.; Bartoli, F.; Caslini, M.; Crocamo, C.; Riva, G.; Carrà, G. Risk and maintenance factors for young women's DSM-5 eating disorders. Arch. Womens Ment. Health 2017, 20, 721-731. [CrossRef]

9. Gardner, R.M. Assessment of body image disturbance in children and adolescents. In Body Image, Eating Disorders, and Obesity in Youth: Assessment, Prevention, and Treatment; American Psychological Association: Washington, DC, US, 2001 ; pp. $193-213$.

10. American Psychological Association (APA). Diagnostic and Statistical Manual of Mental Disorders DSM-5, 5th ed.; American Psychiatric Publishing: Arlington, VA, USA, 2013.

11. Artoni, P.; Chierici, M.L.; Arnone, F.; Cigarini, C.; De Bernardis, E.; Galeazzi, G.M.; Minneci, D.G.; Scita, F.; Turrini, G.; De Bernardis, M.; et al. Body perception treatment, a possible way to treat body image disturbance in eating disorders: A case-control efficacy study. Eat. Weight Disord. 2021, 26, 499-514. [CrossRef]

12. Lewer, M.; Bauer, A.; Hartmann, A.S.; Vocks, S. Different Facets of Body Image Disturbance in Binge Eating Disorder: A Review. Nutrients 2017, 9, 1294. [CrossRef]

13. Ricciardelli, L.A.; McCabe, M.P. Children's body image concerns and eating disturbance: A review of the literature. Clin. Psychol. Rev. 2001, 21, 325-344. [CrossRef]

14. Rohde, P.; Stice, E.; Marti, C.N. Development and predictive effects of eating disorder risk factors during adolescence: Implications for prevention efforts. Int. J. Eat. Disord. 2015, 48, 187-198. [CrossRef] [PubMed]

15. Smolak, L. Body image in children and adolescents: Where do we go from here? Body Image 2004, 1, 15-28. [CrossRef]

16. Esnaola, I.; Rodríguez, A.; Goñi, A. Body dissatisfaction and perceived sociocultural pressures: Gender and age differences. Salud Ment. 2010, 33, 21-29.

17. Baker, L.; Gringart, E. Body image and self-esteem in older adulthood. Ageing Soc. 2009, 29, 977-995. [CrossRef] 
18. Runfola, C.D.; Von Holle, A.; Trace, S.E.; Brownley, K.A.; Hofmeier, S.M.; Gagne, D.A.; Bulik, C.M. Body dissatisfaction in women across the lifespan: Results of the UNC-SELF and Gender and Body Image (GABI) studies. Eur. Eat. Disord Rev. 2013, 21, 52-59. [CrossRef]

19. Tiggemann, M.; McCourt, A. Body appreciation in adult women: Relationships with age and body satisfaction. Body Image 2013, 10, 624-627. [CrossRef]

20. Quittkat, H.L.; Hartmann, A.S.; Düsing, R.; Buhlmann, U.; Vocks, S. Body Dissatisfaction, Importance of Appearance, and Body Appreciation in Men and Women Over the Lifespan. Front. Psychiatry 2019, 10. [CrossRef]

21. Mölbert, S.C.; Thaler, A.; Mohler, B.J.; Streuber, S.; Romero, J.; Black, M.J.; Zipfel, S.; Karnath, H.O.; Giel, K.E. Assessing body image in anorexia nervosa using biometric self-avatars in virtual reality: Attitudinal components rather than visual body size estimation are distorted. Psychol. Med. 2018, 48, 642-653. [CrossRef]

22. Grilo, C.M.; Crosby, R.D.; Machado, P.P. Examining the distinctiveness of body image concerns in patients with anorexia nervosa and bulimia nervosa. Int. J. Eat. Disord. 2019, 52, 1229-1236. [CrossRef]

23. Kling, J.; Kwakkenbos, L.; Diedrichs, P.C.; Rumsey, N.; Frisén, A.; Brandão, M.P.; Silva, A.G.; Dooley, B.; Rodgers, R.F.; Fitzgerald, A. Systematic review of body image measures. Body Image 2019, 30, 170-211. [CrossRef] [PubMed]

24. Cash, T.F. Cognitive-behavioral perspectives on body image. In Body Image: A Handbook of Theory, Research, and Clinical Practice; G. Press: New York, NY, USA, 2002; pp. 38-46.

25. Cash, T.F.; Smolak, L. Body Image: A Handbook of Science, Practice, and Prevention; Guilford Press: New York, NY, USA, 2011.

26. Glashouwer, K.A.; van der Veer, R.M.L.; Adipatria, F.; de Jong, P.J.; Vocks, S. The role of body image disturbance in the onset, maintenance, and relapse of anorexia nervosa: A systematic review. Clin. Psychol. Rev. 2019, 74, 101771. [CrossRef] [PubMed]

27. Cash, T.F.; Deagle III, E.A. The nature and extent of body-image disturbances in anorexia nervosa and bulimia nervosa: A meta-analysis. Int. J. Eat. Disord. 1997, 22, 107-125. [CrossRef]

28. Grogan, S. Body Image: Understanding Body Dissatisfaction in Men, Women and Children, 2nd ed.; Routledge/Taylor \& Francis Group: New York, NY, USA, 2008.

29. Hagman, J.; Gardner, R.M.; Brown, D.L.; Gralla, J.; Fier, J.M.; Frank, G.K.W. Body size overestimation and its association with body mass index, body dissatisfaction, and drive for thinness in anorexia nervosa. Eat. Weight Disord. 2015, 20, 449-455. [CrossRef] [PubMed]

30. Wertheim, E.H.; Paxton, S.J. Body image development in adolescent girls. In Body Image: A Handbook of Science, Practice, and Prevention, 2nd ed.; The Guilford Press: New York, NY, USA, 2011; pp. 76-84.

31. Cornelissen, K.K.; Widdrington, H.; McCarty, K.; Pollet, T.V.; Tovée, M.J.; Cornelissen, P.L. Are attitudinal and perceptual body image the same or different? Evidence from high-level adaptation. Body Image 2019, 31, 35-47. [CrossRef]

32. Mergen, J.; Keizer, A.; Koelkebeck, K.; van den Heuvel, M.R.C.; Wagner, H. Women with Anorexia Nervosa do not show altered tactile localization compared to healthy controls. Psychiatry Res. 2018, 267, 446-454. [CrossRef]

33. Smeets, M.A.M. The Rise and Fall of Body Size Estimation Research in Anorexia Nervosa: A Review and Reconceptualization. Eur. Eat. Disord. Rev. 1997, 5, 75-95. [CrossRef]

34. Garner, D.M.; Olmstead, M.P.; Polivy, J. Development and validation of a multidimensional eating disorder inventory for anorexia nervosa and bulimia. Int. J. Eat. Disord. 1983, 2, 15-34. [CrossRef]

35. Cooper, P.J.; Taylor, M.J.; Cooper, Z.; Fairbum, C.G. The development and validation of the body shape questionnaire. Int. J. Eat. Disord. 1987, 6, 485-494. [CrossRef]

36. Rosen, J.C.; Srebnik, D.; Saltzberg, E.; Wendt, S. Development of a body image avoidance questionnaire. J. Consult. Clin. Psychol. 1991, 3, 32-37. [CrossRef]

37. Hart, E.A.; Leary, M.R.; Rejeski, W.J. The Measurement of Social Physique Anxiety. J. Sport Exerc. Psychol. 1989, 11, 94-104. [CrossRef]

38. Thompson, J.K.; Psaltis, K. Multiple aspects and correlates of body figure ratings: A replication and extension of Fallon and Rozin (1985). Int. J. Eat. Disord. 1988, 7, 813-817. [CrossRef]

39. Gardner, R.M.; Brown, D.L. Body image assessment: A review of figural drawing scales. Pers. Individ. Differ. 2010, 48, 107-111. [CrossRef]

40. Traub, A.C.; Orbach, J. Psychophysical Studies of Body-Image: I. The Adjustable Body-Distorting Mirror. Arch. Gen. Psychiatry 1964, 11, 53-66. [CrossRef] [PubMed]

41. Probst, M.; Vandereycken, W.; Van Coppenolle, H.; Pieters, G. Body size estimation in anorexia nervosa patients: The significance of overestimation. J. Psychosom. Res. 1998, 44, 451-456. [CrossRef]

42. Probst, M. Eating Disorders and Physical Activity: A Complex Relationship. In Physical Activity and Mental Health: A PracticeOriented Approach; Edi Ermes: Milan, Italy, 2014; pp. 101-113.

43. Tovée, M.J.; Benson, P.J.; Emery, J.L.; Mason, S.M.; Cohen-Tovée, E.M. Measurement of body size and shape perception in eating-disordered and control observers using body-shape software. Br. J. Psychol. 2003, 94, 501-516. [CrossRef]

44. Serino, S.; Pedroli, E.; Keizer, A.; Triberti, S.; Dakanalis, A.; Pallavicini, F.; Chirico, A.; Riva, G. Virtual Reality Body Swapping: A Tool for Modifying the Allocentric Memory of the Body. Cyberpsychol. Behav. Soc. Netw. 2016, 19, 127-133. [CrossRef]

45. Slade, P.D.; Russell, G.F. Awareness of body dimensions in anorexia nervosa: Cross-sectional and longitudinal studies. Psychol. Med. 1973, 3, 188-199. [CrossRef] 
46. Fisher, S.; Abdullah, A.; Charvin, I.; Da Fonseca, D.; Bat-Pitault, F. Comparison of body image evaluation by virtual reality and paper-based figure rating scales in adolescents with anorexia nervosa: Retrospective study. Eat. Weight Disord. 2020, 25, 735-743. [CrossRef]

47. Monthuy-Blanc, J.; Bouchard, S.; Ouellet, M.; Corno, G.; Iceta, S.; Rousseau, M. "eLoriCorps Immersive Body Rating Scale": Exploring the Assessment of Body Image Disturbances from Allocentric and Egocentric Perspectives. J. Clin. Med. 2020, 9, 2926. [CrossRef]

48. Gardner, R.M.; Boice, R. A computer program for measuring body size distortion and body dissatisfaction. Behav. Res. Meth. Instrum. Comput. 2004, 36, 89-95. [CrossRef] [PubMed]

49. Corno, G.; Serino, S.; Cipresso, P.; Baños, R.M.; Riva, G. Assessing the Relationship Between Attitudinal and Perceptual Component of Body Image Disturbance Using Virtual Reality. Cyberpsychol. Behav. Soc. Netw. 2018, 21, 679-686. [CrossRef] [PubMed]

50. Provenzano, L.; Porciello, G.; Ciccarone, S.; Lenggenhager, B.; Tieri, G.; Marucci, M.; Dazzi, F.; Loriedo, C.; Bufalari, I. Characterizing Body Image Distortion and Bodily Self-Plasticity in Anorexia Nervosa via Visuo-Tactile Stimulation in Virtual Reality. J. Clin. Med. 2019, 9, 98. [CrossRef] [PubMed]

51. Riva, G.; Gaudio, S. Allocentric lock in anorexia nervosa: New evidences from neuroimaging studies. Med. Hypotheses 2012, 79, 113-117. [CrossRef] [PubMed]

52. Riva, G.; Gaudio, S.; Dakanalis, A. I'm in a virtual body: A locked allocentric memory may impair the experience of the body in both obesity and anorexia nervosa. Eat. Weight Disord. 2014, 19, 133-134. [CrossRef]

53. Riva, G. Neuroscience and eating disorders: The allocentric lock hypothesis. Med. Hypotheses 2012, 78, 254-257. [CrossRef]

54. Riva, G. The Key to Unlocking the Virtual Body: Virtual Reality in the Treatment of Obesity and Eating Disorders. J. Diabetes Sci. 2011, 5, 283-292. [CrossRef]

55. Riva, G. The neuroscience of body memory: From the self through the space to the others. Cortex 2018, 104, 241-260. [CrossRef]

56. Gaudio, S.; Riva, G. Body Image in Anorexia Nervosa: The Link Between Functional Connectivity Alterations and Spatial Reference Frames. Biol. Psychiatry 2013, 73, e25-e26. [CrossRef]

57. Riva, G. Neurobiology of Anorexia Nervosa: Serotonin Dysfunctions Link Self-Starvation with Body Image Disturbances through an Impaired Body Memory. Front. Hum. Neurosci. 2016, 10. [CrossRef]

58. Riva, G. Virtual Reality in Psychological Assessment: The Body Image Virtual Reality Scale. Cyberpsychol. Behav. 1998, 1, 37-44. [CrossRef]

59. Stunkard, A.J.; Sørensen, T.; Schulsinger, F. Use of the Danish Adoption Register for the study of obesity and thinness. Res. Publ. Assoc. Res. Nerv. Ment. Dis. 1983, 60, 115-120. [PubMed]

60. Maïano, C.; Morin, A.J.S.; Monthuy-Blanc, J.; Garbarino, J.-M.; Ninot, G. Development and validity of a very short form of the Eating Disorder Inventory. Compr. Psychiatry 2016, 65, 141-149. [CrossRef] [PubMed]

61. Cicchetti, D.V. Guidelines, criteria, and rules of thumb for evaluating normed and standardized assessment instruments in psychology. Psychol. Assess. 1994, 6, 284-290. [CrossRef]

62. Maïano, C.; Morin, A.J.S.; Eklund, R.C.; Monthuy-Blanc, J.; Garbarino, J.-M.; Stephan, Y. Construct Validity of the Social Physique Anxiety Scale in a French Adolescent Sample. J. Pers. Assess. 2010, 92, 53-62. [CrossRef]

63. Maïano, C.; Morin, A.J.S.; Monthuy-Blanc, J.; Garbarino, J.-M. The Body Image Avoidance Questionnaire: Assessment of its construct validity in a community sample of French adolescents. Int. J. Behav. Med. 2009, 16, 125-135. [CrossRef]

64. Pellizzer, M.L.; Tiggemann, M.; Waller, G.; Wade, T.D. Measures of body image: Confirmatory factor analysis and association with disordered eating. Psychol Assess. 2018, 30, 143-153. [CrossRef] [PubMed]

65. Bouchard, S.; Robillard, G.; Renaud, P.; Bernier, F. Exploring new dimensions in the assessment of virtual reality induced side effects. J. Comput. Inf. Technol. 2011, 1, 20-32.

66. Bouchard, S.; Berthiaume, M.; Robillard, G.; Forget, H.; Daudelin-Peltier, C.; Renaud, P.; Blais, C.; Fiset, D. Arguing in Favor of Revising the Simulator Sickness Questionnaire Factor Structure When Assessing Side Effects Induced by Immersions in Virtual Reality. Front. Psychiatry 2021, 12, 739742. [CrossRef]

67. Leduc, G.; Gilbert, J.-A.; Ayotte, A.; Moreau, N.; Drapeau, V.; Lemoyne, J.; Monthuy-Blanc, J.; Tremblay, J.; Mathieu, M.-E. The FitSpirit approach for increasing physical activity in canadian teenage girls: Protocol of a longitudinal, quasi-experimental study. BMC Public Health 2021, 21, 229. [CrossRef]

68. Faul, F.; Erdfelder, E.; Lang, A.G.; Buchner, A. G*Power 3: A flexible statistical power analysis program for the social, behavioral, and biomedical sciences. Behav Res. Methods 2007, 39, 175-191. [CrossRef] [PubMed]

69. Cohen, J. Statistical Power Analysis for the Behavioral Sciences, 2nd ed.; 12 Lawrence Erlbaum Associates Inc.: Hillsdale, NJ, USA, 1988; p. 13.

70. Gardner, R.M.; Brown, D.L. Body size estimation in anorexia nervosa: A brief review of findings from 2003 through 2013. Psychiatry Res. 2014, 219, 407-410. [CrossRef] [PubMed]

71. Fischer, C.; Malycha, C.P.; Schafmann, E. The Influence of Intrinsic Motivation and Synergistic Extrinsic Motivators on Creativity and Innovation. Front. Psychol. 2019, 10, 137. [CrossRef] [PubMed]

72. Hall, S. Adolescence: Its Psychology and Its Relation to Physiology, Anthropology, Sociology, Sex, Crime, Religion and Education. Am. J. Psychiatry 1904, 61, 375-381. [CrossRef] 
73. Tiggemann, M.; Lynch, J.E. Body image across the life span in adult women: The role of self-objectification. Dev. Psychol. 2001, 37, 243-253. [CrossRef] [PubMed]

74. Rodgers, R.F.; Damiano, S.R.; Wertheim, E.H.; Paxton, S.J. Media exposure in very young girls: Prospective and cross-sectional relationships with BMIz, self-esteem and body size stereotypes. Dev. Psychol. 2017, 53, 2356-2363. [CrossRef] [PubMed]

75. Riva, G. Out of my real body: Cognitive neuroscience meets eating disorders. Front. Hum. Neurosci. 2014, 8. [CrossRef]

76. Dakanalis, A.; Timko, A.C.; Clerici, M.; Riva, G.; Carrà, G. Objectified Body Consciousness (OBC) in Eating Psychopathology. Assessment 2017, 24, 252-274. [CrossRef]

77. Dakanalis, A.; Zanetti, M.A.; Riva, G.; Clerici, M. Psychosocial moderators of the relationship between body dissatisfaction and symptoms of eating disorders: A look at a sample of young Italian women. Eur. Rev. Appl. Psychol. 2013, 63, 323-334. [CrossRef]

78. Noll, S.M.; Fredrickson, B.L. A mediational model linking self-objectification, body shame and disordered eating. Psychol. Women Q. 1998, 22, 623-636. [CrossRef]

79. Dakanalis, A.; Riva, G. Mass media, body image and eating disturbances: The underline mechanism through the lens of the objectification theory. In Body image: Gender Differences, Sociocultural Influences and Health Implication; Latzer, J., Merrick, J., Stein, D., Eds.; Nova Science: New York, NY, USA, 2013; pp. 217-236.

80. Craig, A.D. How do you feel? Interoception: The sense of the physiological condition of the body. Nat. Rev. Neurosci. 2002, 3, 655-666. [CrossRef] [PubMed]

81. Garner, D.M.; Olmsted, M.P.; Polivy, J. The Eating Disorder Inventory: A Measure of Cognitive-Behavioral Dimensions of Anorexia. In Anorexia Nervosa: Recent Developments in Research; Alan R. Liss, Inc.: New York, NY, USA, 1983; pp. 173-184.

82. Oswald, A.; Chapman, J.; Wilson, C. Do interoceptive awareness and interoceptive responsiveness mediate the relationship between body appreciation and intuitive eating in young women? Appetite 2017, 109, 66-72. [CrossRef] [PubMed]

83. Clausen, L.; Rosenvinge, J.H.; Friborg, O.; Rokkedal, K. Validating the Eating Disorder Inventory-3 (EDI-3): A Comparison Between 561 Female Eating Disorders Patients and 878 Females from the General Population. J. Psychopathol. Behav. Assess. 2011, 33, 101-110. [CrossRef] [PubMed]

84. Fassino, S.; Pierò, A.; Gramaglia, C.; Abbate-Daga, G. Clinical, psychopathological and personality correlates of interoceptive awareness in anorexia nervosa, bulimia nervosa and obesity. Psychopathology 2004, 37, 168-174. [CrossRef]

85. Jacquemot, A.M.M.C.; Park, R. The Role of Interoception in the Pathogenesis and Treatment of Anorexia Nervosa: A Narrative Review. Front. Psychiatry 2020, 11. [CrossRef]

86. Khalsa, S.S.; Craske, M.G.; Li, W.; Vangala, S.; Strober, M.; Feusner, J.D. Altered interoceptive awareness in anorexia nervosa: Effects of meal anticipation, consumption and bodily arousal. Int. J. Eat. Disord. 2015, 48, 889-897. [CrossRef]

87. Tribole, E.; Resch, E. Intuitive Eating: A Revolutionary Anti-Diet Approach, 4th ed.; St. Martin's Essentials: New York, NY, USA, 2020.

88. Piran, N.; Neumark-Sztainer, D. Yoga and the experience of embodiment: A discussion of possible links. Eat. Disord 2020, 28, 330-348. [CrossRef]

89. Tribole, E.; Resch, E. Intuitive Eating: A Recovery Book for the Chronic Dieter: Rediscover the Pleasures of Eating and Rebuild Your Body Image, 1st. ed.; Diane Pub Co: Collingdale, PA, USA, 1995.

90. Monthuy-Blanc, J.; Lemieux, V.; Thériault, J.; Rousseau, M. Exploratory Study: A Blind Integrated School-Based Prevention Program on Eating Disorders and Obesity. Can. J. Commun. Ment. Health 2021, 39, 61-84. [CrossRef]

91. Richard, A.; Meule, A.; Friese, M.; Blechert, J. Effects of Chocolate Deprivation on Implicit and Explicit Evaluation of Chocolate in High and Low Trait Chocolate Cravers. Front. Psychol. 2017, 8. [CrossRef]

92. Smitham, D.L.A. Evaluating an Intuitive Eating Program. for Binge Eating Disorder: A Benchmarking Study; University of Notre Dame: Notre Dame, IN, USA, 2008.

93. Diers, L.; Rydell, S.A.; Watts, A.; Neumark-Sztainer, D. A yoga-based therapy program designed to improve body image among an outpatient eating disordered population: Program description and results from a mixed-methods pilot study. Eat. Disord 2020 28, 476-493. [CrossRef]

94. Andrieu, B. Sentir sa santé. In Les Sensations de Santé: Pour une Épistémologie des Pratiques Corporelles du Sujet de Santé; Presses Universitaires de Nancy: Nancy, France, 2011; pp. 259-282.

95. Jordana Ovejero, O.; Espinoza Guzmán, P.; González González, M.; Subiza Pérez, I.; Becerra Castro, A.; Raich Escursell, R.M.; Mora Giral, M.S. Universal prevention program of eating, weight and body image problems in adolescents: A 12-month follow-up. Psicothema 2020, 32, 204-213. [PubMed]

96. Fonseca-Baeza, S.; Corno, G.; Baños, R.M. An intervention protocol proposal to modify the body image disturbance using Virtual Reality. Calid. Vida Salud 2018, 11, 48-61.

97. Malighetti, C.; Chirico, A.; Serino, S.; Cavedoni, S.; Matamala-Gomez, M.; Stramba-Badiale, C.; Mancuso, V.; Corno, G.; Polli, N.; Cacciatore, C.; et al. Manipulating body size distortions and negative body-related memories in patients with Anorexia Nervosa: A virtual reality-based pilot study. Annu. Rev. Cyber Ther. Telemed. 2020, 18, 177-181.

98. Compte, E.; Sepulveda, A.; Torrente, F. Approximations to an Integrated Model of Eating Disorders and Muscle Dysmorphia among University Male Students in Argentina. Men Masc. 2018, 23, 288-305. [CrossRef]

99. Malcolm, A.; Pikoos, T.; Castle, D.J.; Labuschagne, I.; Rossell, S.L. Identity and shame in body dysmorphic disorder as compared to obsessive-compulsive disorder. J. Obs. Compuls. Relat. Disord. 2021, 31, 100686. [CrossRef]

100. Szerman, N.; Peris, L. Precision Psychiatry and Dual Disorders. J. Dual Diagn. 2018, 14, 237-246. [CrossRef] 
101. Tiggemann, M.; Martins, Y.; Churchett, L. Beyond muscles: Unexplored parts of men's body image. J. Health Psychol. 2008, 13, 1163-1172. [CrossRef]

102. Ferrer-García, M.; Gutiérrez-Maldonado, J. The use of virtual reality in the study, assessment, and treatment of body image in eating disorders and nonclinical samples: A review of the literature. Body Image 2012, 9, 1-11. [CrossRef]

103. Sherman, D.K.; Iacono, W.G.; Donnelly, J.M. Development and validation of body rating scales for adolescent females. Int. J. Eat. Disord 1995, 18, 327-333. [CrossRef] 